\title{
Expression of mouse small interfering RNAs in lettuce using artificial microRNA technology
}

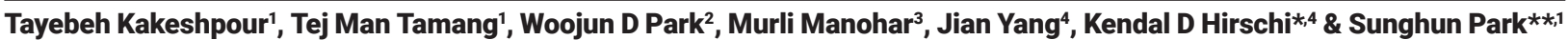

\begin{abstract}
Artificial miRNA technology enables the generation of siRNAs to regulate the expression of targeted genes. However, the application of siRNAs to alter gene expression is challenging due to their instability and requires a means to efficiently deliver siRNAs into the host. Here, we report that the siRNAs targeted to animal mRNAs can be heterologously expressed and stably produced in lettuce. We have modified rice miRNA precursors to produce siRNAs in lettuce with the potential to target mRNAs of mouse complement 3 (C3) and coagulation factor 7 (CF7). Expression of primary and mature siRNAs in the transgenic lettuce lines was confirmed via Sanger sequencing. Our study demonstrates an applicable tool to alter gene expression in the targeted host and has potential utility in siRNA-based oral therapeutics.
\end{abstract}

\section{METHOD SUMMARY}

We customized a rice miRNA backbone, Osa-MIR528, to construct plant expression vectors containing amiRNAs targeting mouse messenger RNAs. This system, which previously was used for amiRNA expression in monocots, now is used to generate amiRNAs in agriculturally important dicots such as lettuce, enabling production of siRNAs targeting various medically important proteins that could potentially be delivered through the diet.

\section{KEYWORDS}

amiRNA technology $\cdot$ lettuce $\cdot$ mouse $\cdot$ PCR - therapeutic dietary siRNA

'Department of Horticulture \& Natural Resources, Kansas State University, Manhattan, KS 66506, USA; ${ }^{2}$ Department of Molecular \& Human Genetics, Baylor College of Medicine, Houston, TX77030, USA; ${ }^{3}$ Boyce Thompson Institute, Cornell University, Ithaca, NY 14853, USA; ${ }^{4}$ Agricultural Research Service, US Department of Agriculture; Department of Pediatrics, Baylor College of Medicine, Children's Nutrition Research Center, Houston, TX 77030,USA; *Author for correspondence: kendalh@bcm.edu; **Author for correspondence:shpark@ksu.edu

BioTechniques 68: 214-218 (April 2020) 10.2144/ btn-2019-0139
RNA interference is a natural process by which siRNA or miRNA molecules inhibit gene expression or translation by targeting messenger RNA molecules. siRNAs are 19-27-bp, double-stranded molecules that can be derived from double-stranded RNAs or hairpin RNA splicing [1,2]. Exogenously introduced siRNAs can be used to knock down virtually any gene in host cells; hence, RNAi has proven to be a valuable technology for the functional analysis of genes. Development of therapeutic applications of RNAi in gene therapy to reduce the expression of disease-related proteins further highlight the importance of RNAi technology [3]; however, there remain several obstacles to the successful implementation of RNAi. Among others, fast degradation and the instability of siRNA in the host have remained major hurdles [4]. Many attempts, including the application of lipid-based nanoparticles, have been made to achieve efficient delivery to prevent siRNA degradation [5]. Recently, several studies have investigated the ingestion of bioactive and bioavailable miRNA through plant-based diets, opening up new avenues for applying RNAi technology in medicine [4]. Genetically engineered plants producing biodrugs may offer a healthier and more economical alternative to drugs made through animal cell culture or synthesized chemically [6]. Additionally, plantbased siRNAs could be more stable than their synthetic counterparts [7]. The feasibility of dietary amiRNA technology is supported by several studies demonstrating that native miRNAs or small RNAs in plants can survive gut digestion and enter circulation. For example, a honeysuckle diet in mice enhanced detection of MIR2911 and MIR168a [8] and plant miRNA can be detected in human plasma after the consumption of watermelon [9]. A rice-based miRNA,
MIR168a, has also been shown to inhibit the expression of targeted LDLRAP1 protein in the liver through the dietary intake of rice [10].

The genesis of these studies was a desire to provide precise tools for examining the relationship between dietary consumption of genetic material and changes in gene expression. This work establishes the importance of plant-based foods expressing siRNAs that target genes in the mouse liver. Any changes in liver gene expression could be quantified using simple, established assays that monitor expression of the functional proteins. The transgenic lettuce lines engineered here set the table for future dietary studies. Blood coagulation regulated by mammalian complement factors, including complement 3 (C3) and coagulation factor 7 (CF7) in liver, is a vital process to stop bleeding caused by injury to blood vessels [11]. However, excessive production of $\mathrm{C} 3$ and CF7 has also been shown to cause blood clots, which can pose significant health risks and lead to death due to improper functioning of the cardiovascular system [12,13].

In this study, lettuce was used to produce dietary amiRNAs designed to target $C 3$ and CF7 messenger RNAs. An endogenous rice miRNA backbone, a 245-bp fragment of osa-MIR528 [14,15], was customized to design amiRNAs targeting $\mathrm{C} 3$ and CF7 proteins of mouse. C3 and CF7 amiRNA sequences were manually designed with annotation of mouse genome sequences and the 21 bp of osa-MIR528 were replaced by C3 and CF7 amiRNA sequences using PCR (Figure 1A).

Three pairs of primers were designed to replace the $21 \mathrm{bp}$ of osa-MIR528 with target siRNAs (Supplementary Table 1). The osa-MIR528 backbone was used as a template for PCR. The first PCRs using designed primer sets resulted in three 


\section{BioTechniques}

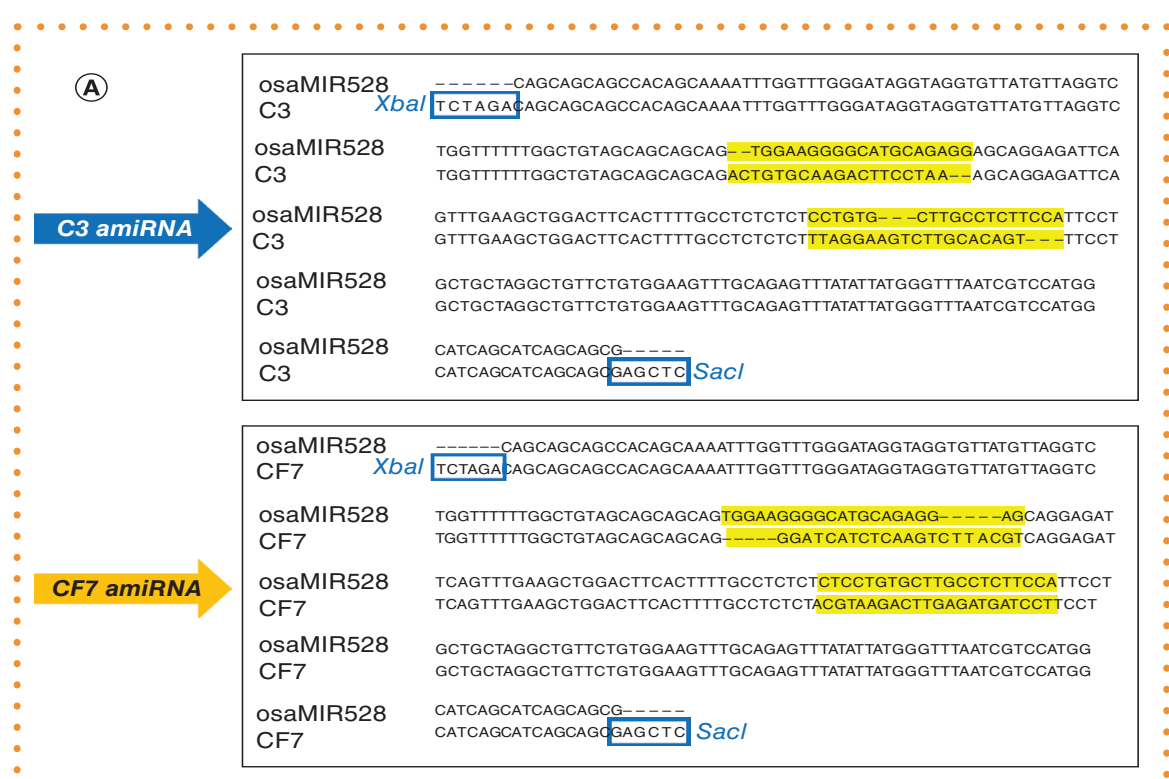

(B)

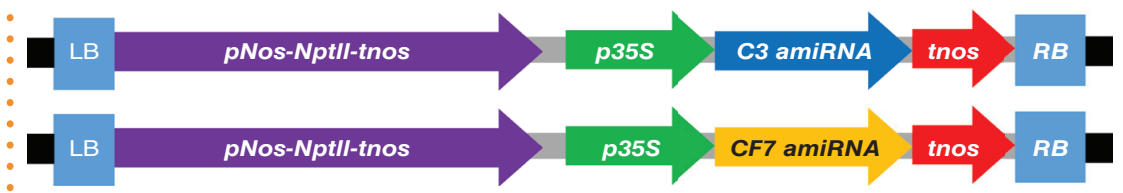

Figure 1. Plant expression vectors harboring amiRNAs designed to target $\mathrm{C} 3$ and $\mathrm{CF}$ messenger RNAs of mouse using a 245-bp fragment of osa-MIR528. (A) The 21 bp of osa-MIR528 (black letters) from the stem loop sequence was replaced by C3 (top panel) and CF7 (bottom panel) sequences (red letters) to create siRNAs, respectively. The cloning sites used were $\mathrm{Xbal}$ and $\mathrm{Sacl}$ which insert a fragment of approximately $259 \mathrm{bp}$ after restriction digestion. (B) Map of T-DNA region of the binary vectors (top panel, $p C 3 a m i R N A$; bottom panel, $p C F 7 a m i R N A$ ) used for transformation.

LB: Left border; NPTII: Neomycin phosphotransferase; p35S: Cauliflower mosaic virus 35S promoter; pNos: Nopaline synthase promoter; RB: Right border; tnos: Nopaline synthase terminator.

DNA fragments containing target siRNAs. Finally, fusion PCR on the three PCR products produced one DNA fragment for subsequent cloning (Supplementary Figure 1). C3 and CF7 amiRNA fragments were then inserted into plant expression vector $\mathrm{PBICaMV}$ under the control of cauliflower mosaic virus $35 \mathrm{~S}$ constitutive promoter and nopaline synthase terminator (Figure 1B). Plant expression vectors harboring amiRNAs were then transformed into One Shot ${ }^{\circledR}$ TOP10 Chemically Competent $E$. coli cells (Thermo Fisher Scientific, MA, USA) and the transformation was confirmed by both antibiotic selection and PCR. Vectors were transformed into Agrobacterium tumefaciens strain LBA4404 using the freeze-thaw method [16] and confirmed by both antibiotic selection and PCR. Each construct (C3 amiRNA, CF7 amiRNA, pBICaMV and osa-MiR528) was transformed into Lactuca sativa L. var. Simpson using Agrobacterium-mediated transfor- mation as described previously [17]. Briefly, surface sterilized seeds were germinated on Murashige and Skoog (MS) [18] inorganic salt medium containing $30 \mathrm{~g} / \mathrm{l}$ sucrose $(\mathrm{pH}$ 5.7) and $8 \mathrm{~g} / \mathrm{l}$ agar (PhytoTechnology, KS, USA). Six-week-old in vivo grown lettuce leaves were excised and precultured on MS inorganic salts with $100 \mathrm{mg} / \mathrm{l}$ inositol, MS vitamins, $30 \mathrm{~g} / \mathrm{l}$ sucrose, $2 \mathrm{mg} / \mathrm{l} \mathrm{N}-6(2-$ isopentenyl)-adenine, $0.1 \mathrm{mg} / \mathrm{l}$ indole acetic acid and $8 \mathrm{~g} / \mathrm{l}$ agar for 1 day. Then, leaves were inoculated with Agrobacterium for $1 \mathrm{~min}$ and recultured on the same medium for 3 days. Leaf sections were afterward transferred on selection medium with MS inorganic salts, $30 \mathrm{~g} / \mathrm{l}$ sucrose, $100 \mathrm{mg} / \mathrm{l}$ inositol, MS vitamins, $0.4 \mathrm{mg} / \mathrm{l}$ 6-benzyl-aminopurine, $0.05 \mathrm{mg} / \mathrm{l}$ naphthaleneacetic acid, $100 \mathrm{mg} / \mathrm{l}$ kanamycin, $250 \mathrm{mg} / \mathrm{l}$ Clavamox ${ }^{\circledR}$ (Zoetis, NJ, USA) and $8 \mathrm{~g} / \mathrm{l}$ agar. Cultures were kept at $22^{\circ} \mathrm{C}$ with a 14 -h photoperiod for $6-8$ weeks for shoot regeneration, then shoots were transferred into rooting medium containing MS inorganic salt medium, $30 \mathrm{~g} / \mathrm{l}$ sucrose $(\mathrm{pH}$ 5.7), $100 \mathrm{mg} / \mathrm{l}$ kanamycin, $250 \mathrm{mg} / \mathrm{l}$ Clavamox and $2 \mathrm{~g} /$ I Gelzan $^{\text {TM }}$ (PhytoTech Labs, KS, USA) for another 6 weeks. Lettuce seedlings were afterward established in soil and moved to growth chambers at $16-18^{\circ} \mathrm{C}$ with a $14-\mathrm{h}$ photoperiod. The plants were watered once every week with Miracle-Gro ${ }^{\circledR}$ Tomato Plant Food (ScottsMiracle-Gro, NY, USA). Lettuce was selected, as it has a rapid life cycle and can be easily cultivated in indoor spaces. Moreover, lettuce is the top grossing fresh market vegetable crop and is an excellent dietary source of vitamins, as well as carotenoids [19].

We generated three independent $\mathrm{C} 3$ (C3siRNA-1,-2 and -3) and CF7 (CF7siRNA-1, -2 and -3 ) transgenic lines that self-pollinated and the progeny lines were genotyped for the presence of T-DNA (Figure 2A). The $245 \mathrm{bp}$ of the vector including amiRNA sequences were used as a size control marker to confirm insertion of amiRNA sequences into genomic DNA. DNA from all transgenic lines showed the 245-bp band corresponding to the marker size. No PCR product was detected for control plants (Figure 2B). The 3-month-old C3-and CF7-expressing lettuce plants were comparable to wild-type plants and the phenotype and yield of the C3- and CF7-expressing lettuce plants were indistinguishable from those of the wild-type plants grown under normal growth conditions (Figure 2C). Expression of $\mathrm{C} 3$ and $C F 7$ does not appear to have any adverse effects on overall plant morphology.

To determine transgene copy number in transformed plants, absolute quantification using quantitative real-time PCR was performed. Total reaction volume for each sample was $10 \mu \mathrm{l}$ and the samples contained $60 \mathrm{ng}$ of genomic DNA, $30 \mathrm{pmol}$ of forward and reverse primers and $7.3 \mu$ of $\mathrm{iQ}^{\text {TM }}$ SYBR ${ }^{\circledR}$ Green Supermix (Bio-Rad Laboratories, CA, USA). Forward and reverse primers were designed to amplify the osa-MI-528 backbone within the T-DNA region (Table 1). The following thermal cycle was performed using a CFX96 Bio-Rad thermal cycler: $94^{\circ} \mathrm{C}$ for $10 \mathrm{~min}$ followed by 34 cycles of $95^{\circ} \mathrm{C}$ for $30 \mathrm{~s}, 58^{\circ} \mathrm{C}$ for $20 \mathrm{~s}$ and $72^{\circ} \mathrm{C}$ for $30 \mathrm{~s}$. Two technical replications were used. A series of fivefold dilutions of genomic DNA were plotted against cycle threshold $\left(C_{t}\right)$ values to generate a standard curve (Supplementary 

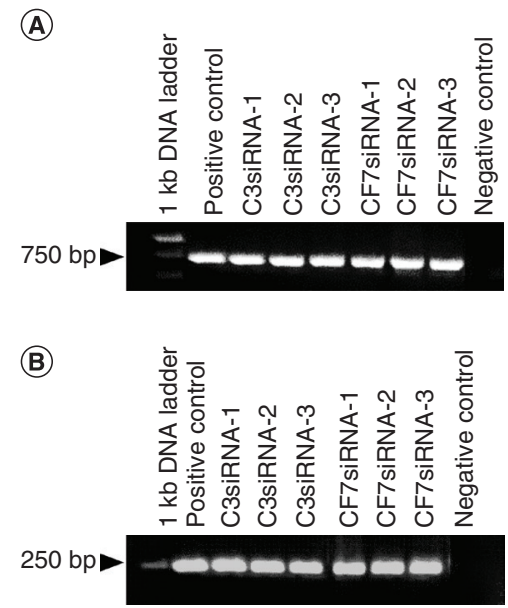

(C)
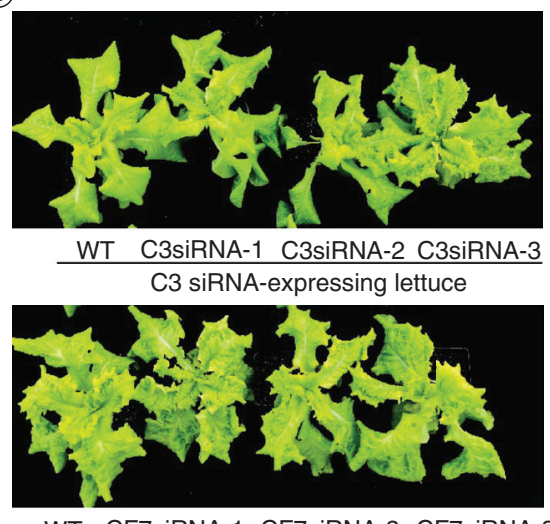

WT CF7siRNA-1 CF7siRNA-2 CF7siRNA-3 CF7 siRNA-expressing lettuce

Figure 2. Molecular and phenotype analyses of C3siRNA- and CF7siRNA-expressing lettuces. (A) PCR detection of NPTII gene in genomic level of transformed lettuce plants. (B) PCR detection of C3 and CF7 artificial microRNA inserts in lettuce genomic DNA. Positive control, artificial microRNAs; negative control, wild-type lettuce. Primer sequences are shown in Table 1. (C) Phenotypes of C3siRNA-expressing, CF7siRNA-expressing and WT lettuce plants. NPTII: Neomycin phosphotransferase II gene; WT: Wild-type.

Figure $2 A$ ). The $C_{t}$ values of the samples and the slope and intercept of the standard curve were used to calculate transgene copy number as:

$\mathrm{C}_{\mathrm{t}(\text { samples })}=$ slope $_{(\text {standard.curve })} \times \log _{(\text {copy.number })}+$ intercept ${ }_{\text {(standard.curve) }}$

Transgene copy number analysis also confirmed successful integration of two to six T-DNA copies within the genome of the transgenic lettuce lines (Supplementary Figure 2B).

Transgenic plants confirmed by PCR were further subjected to semiquantitative RT-PCR to check whether integrated
T-DNA was successfully transcribed in the lettuce. Total RNA was isolated using TRIzol $^{\mathrm{TM}}$ reagent (Thermo Fisher Scientific) and then treated with RNAse-free DNAse I to eliminate genomic DNA contamination. One microgram of RNA was used for cDNA synthesized using Oligo (dT) Primer (Bioline, London, UK) following the kit manufacturer's instructions (RevertAid First Strand cDNA Synthesis Kit, Thermo Fisher Scientific). The semiquantitative RT-PCR was carried out using a specific set of primers designed to amplify 245 bp containing primary amiRNA sequences from the expression cassette. The following thermocycler program was used to detect our target: $94^{\circ} \mathrm{C}$ for $5 \mathrm{~min}$ followed by 35 cycles of $94^{\circ} \mathrm{C}$ for $1 \mathrm{~min}, 59^{\circ} \mathrm{C}$ for $45 \mathrm{~s}, 72^{\circ} \mathrm{C}$ for $1 \mathrm{~min}$ and $72^{\circ} \mathrm{C}$ for $10 \mathrm{~min}$. Semiquantitative RT-PCR showed $245 \mathrm{bp}$ bands corresponding to the expected size of primary amiRNAs. No PCR product was detected in the control plants (Figure 3A).

Next, we tested whether primary amiRNA generates mature amiRNA. Due to the short length of mature amiRNAs, their detection using standard PCR was not possible. To detect mature amiRNA in transgenic plants, a set of stem-loop primers was used in the reverse transcriptase process to add a 50-bp molecule to mature amiRNAs. cDNA was synthesized using stem-loop RT primer with the complement of six nucleotides from the 3 ' end of mature amiRNA [21]. Reverse transcription was performed in the following sequential incubation: 40 cycles of $95,85,75,65,55,45,35,25$ and $15^{\circ} \mathrm{C}$ for $15 \mathrm{~s}$ each to ensure proper formation of the hairpin structure and annealing of RT primers, followed by $42^{\circ} \mathrm{C}$ for $5 \mathrm{~min}$ and $75^{\circ} \mathrm{C}$ for $10 \mathrm{~min}$. To design forward primers, the first 12-14 nucleotides from the 5' end of mature amiRNAs were selected, then six or seven additional $5^{\prime}$ nucleotides were added to achieve $a T_{m}$ of $60^{\circ} \mathrm{C}$. A universal reverse primer within the stem loop was used [21]. The following end point PCR program was run for amiRNA amplification: $94^{\circ} \mathrm{C}$ for $2 \mathrm{~min}$ followed by 40 cycles of $94^{\circ} \mathrm{C}$ for $15 \mathrm{~s}$ and $57^{\circ} \mathrm{C}$ for $30 \mathrm{~s}$. End point PCR showed a band with the expected size of $55 \mathrm{bp}$, but no band was observed in control plants (Figure 3B). Primer sequences used for all PCR analyses are listed in Table 1. To further validate our results, end point PCR products containing

\section{Table 1. Primer sequences.}

\section{Experiment}

\section{NptII PCR}

Primary amiRNA PCR and copy number qPCR

Primary amiRNA semiquantitative RT-PCR

Quantitative real-time PCR internal control (tonoplast intrinsic protein 41)

Mature amiRNA end point PCR and quantitative real-time PCR

\begin{tabular}{l|l|l|}
\hline - Complement 3 & $5^{\prime}$-ctcagcccactgtgcaagac-3' & $5^{\prime}$-ccagtgcagggtccgaggta-3' \\
\hline - Coagulation factor 7 & $5^{\prime}$-cacgccgggatcatctcaa-3' & $5^{\prime}$-ccagtgcagggtccgaggta-3' \\
\hline Stem-loop reverse transcriptase & \multicolumn{2}{|l|}{} \\
\hline - Complement 3 & $5^{\prime}$-gtcgtatccagtgcagggtccgaggtattcgcactggatacgacctttag-3' \\
\hline - Coagulation factor 7 & $5^{\prime}$-gtcgtatccagtgcagggtccgaggtattcgcactggatacgacacgtaa-3' \\
\hline
\end{tabular}

\section{Forward primer Reverse primer}

\begin{tabular}{|l|l|}
\hline 5'-gaggctattcggctatgactg-3' & 5'-atcgggagcggcgataccgta-3' \\
\hline 5'-cagcagcagccacagcaaaat-3' & 5'-atggcatcagcatcagcagc-3' \\
\hline 5'-cagcagcagccacagcaaaat-3' & 5'-atggcatcagcatcagcagc-3' \\
\hline 5'-gagagatttgctggagggaaacta-3' & 5'-cctttgactgatgatgtttgga-3' \\
\hline
\end{tabular}




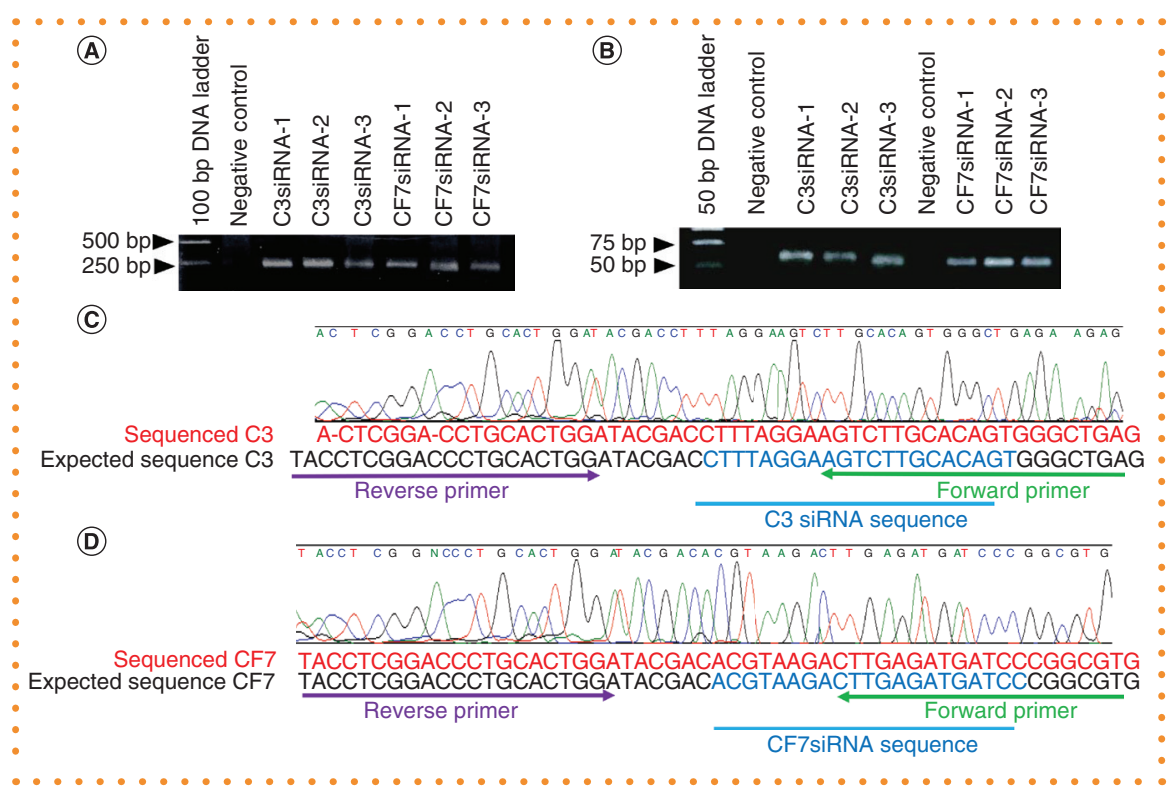

Figure 3. PCR detection of primary and mature amiRNAs and Sanger sequencing of mature $C 3$ and CF7 amiRNAs using stem-loop universal reverse primer. (A) RT-PCR detection of primary C3 and CF7 amiRNAs from C3siRNA- and CF7siRNA-expressing lettuces. Negative control, wild-type lettuce. (B) Stem-loop end point PCR detection of mature C3 and CF7 amiRNAs from C3siRNA- and CF7siRNA-expressing lettuces. Negative control, wild-type lettuce. Primer sequences are shown in Table 1. (C) Expected and obtained sequences of mature C3 amiRNA. (D) Expected and obtained sequences of mature CF7 amiRNA.

mature amiRNA were sequenced and analyzed. Sequencing data also confirmed the generation of mature amiRNAs (Figure $3 \mathrm{C}$ $\& D)$. These results indicate that primary amiRNAs were produced and cleaved to functional amiRNAs.

To quantify relative expression levels of mature $\mathrm{C} 3$ and CF7 amiRNAs, qPCR analysis was carried out. Tonoplast intrinsic protein 41 (TIP41) was used as a reference gene to normalize $C_{t}$ values. For each transgenic line, approximately $35 \mathrm{mg}$ of lettuce leaf tissue was used for RNA isolation, and average yields of total RNA ranged from approximately 20 to $50 \mu \mathrm{g} ; 2 \mu \mathrm{g}$ of total RNA was used to synthesize cDNA. Each reaction contained $8 \mu \mathrm{l}$ of CDNA (1:6 dilution), $0.35 \mu \mathrm{l}$ of each forward and reverse primer $(10 \mathrm{mM})$ and $11.3 \mu$ l of iQ SYBR Green Supermix in a total volume of $20 \mu \mathrm{l}$. qPCR was performed in two technical replications using a CFX96 Bio-Rad thermal cycler with the following program: $95^{\circ} \mathrm{C}$ for $3 \mathrm{~min}$, followed by 39 cycles of $95^{\circ} \mathrm{C}$ for $30 \mathrm{~s}, 55^{\circ} \mathrm{C}$ for $20 \mathrm{~s}$ and $72^{\circ} \mathrm{C}$ for $30 \mathrm{~s} . \mathrm{C}_{\mathrm{t}}$ values were analyzed using the 2-uct method [22]. Transgenic lines with the lowest expression level (the highest $C_{t}$ value) were selected as controls to calculate the relative expression levels of amiRNAs for each transgenic line and compare the fold changes in expression. The results showed that C3siRNA-2 lettuce had the highest expression level compared with the C3siRNA-1 and -3 lines and CF7siRNA-2 lettuce had the highest expression level compared with C7siRNA-1 and -3 . Relatively lower $C_{t}$ values of amiRNAs compared with internal controls indicate that mature amiRNAs are expressed in detectable levels and higher than a housekeeping TIP-41 gene (Supplementary Figure 3). The data imply the high possibility of adequate production for further feeding experiments.

In our study, we generated C3- and CF7-expressing lettuce plants. Expression of primary and mature amiRNAs in the transgenic lettuce was verified by semiquantitative RT-PCR and end point PCR, respectively, and was further confirmed via sequencing. Stable production of animal siRNAs in edible leafy plants with high biomass and delivering them as dietary siRNAs has great potential to overcome the limitations of unstable naked siRNA applications.

\section{SUPPLEMENTARY DATA}

To view the supplementary data that accompany this paper please visit the journal website at: www.future-science. com/doi/suppl/10.2144/btn-2019-0139

\section{AUTHOR CONTRIBUTIONS}

S Park and KD Hirschi designed the experiments. T Kakeshpour, TM Tamang, WD Park, M Manohar and J Yang performed the experiments. T Kakeshpour, TM Tamang and S Park analyzed the data. All authors contributed to writing the manuscript.

\section{ACKNOWLEDGMENTS}

We thank JK Park for excellent technical assistance regarding lettuce transformation.

\section{FINANCIAL \& COMPETING INTERESTS DISCLOSURE}

This project was funded by Agriculture and Food Research Initiative competitive grant number 2016-67017-24712 from the US Department of Agriculture (USDA) National Institute of Food and Agriculture (S Park), National Science Foundation grant number IOS-1741090 (S Park), and the USDA Agricultural Research Service under cooperative agreement number 58-3092-5-001 (KD Hirschi). The contents of this publication do not necessarily reflect the views or policies of the USDA, nor does mention of trade names, commercial products, or organizations imply endorsement by the US Government. The authors have no other relevant affiliations or financial involvement with any organization or entity with a financial interest in or financial conflict with the subject matter or materials discussed in the manuscript apart from those disclosed.

No writing assistance was utilized in the production of this manuscript.

\section{OPEN ACCESS}

This work is licensed under the AttributionNonCommercial-NoDerivatives 4.0 Unported License. To view a copy of this license, visit http://creativecommons.org/licenses/ by-nc-nd/4.0/

\section{REFERENCES}

Papers of special note have been highlighted as: • of interest; •• of considerable interest

1. Bobbin ML, Rossi JJ. RNA interference (RNAi)-based therapeutics: delivering on the promise? Annu. Rev. Pharmacol. 56, 103-122 (2016).

2. Voinnet O, Pinto YM, Baulcombe DC. Suppression of gene silencing: a general strategy used by diverse USA 96(24), 14147-14152 (1999).

3. Kedmi R, Veiga N, Ramishetti S et al. A modular platform for targeted RNAi therapeutics. Nat. Nanotech- 
nol. 13(3), 214-219 (2018).

4. Tatiparti K, Sau S, Kashaw SK, lyer AK. siRNA Delivery strategies: a comprehensive review of recent developments. Nanomaterials (Basel) 7(4), E77 (2017).

5. Joga MR, Zotti MJ, Smagghe G, Christiaens O. RNAi efficiency, systemic properties, and novel delivery methods for pest insect control: what we know so far. Front Physiol. 7, 553 (2016).

6. Hirschi KD, Pruss GJ, Vance V. Dietary delivery: a new avenue for microRNA therapeutics? Trends Biotechnol. 33(8), 431-432 (2015).

- Discusses therapeutic implications of plant-based RNAs.

7. Yang J, Elbaz-Younes I, Primo C, Murungi D, Hirschi $\mathrm{KD}$. Intestinal permeability, digestive stability and ora bioavailability of dietary small RNAs. Sci. Rep. 8(1) 10253 (2018).

8. Yang J, Farmer LM, Agyekum AaA, Hirschi KD. Detection of dietary plant-based small RNAs in animals. Cell of dietary plant-based small
Res. 25(4), 517-520 (2015).

-. Demonstrates a plant-based dietary RNA can be detected in consumers.

9. Liang HW, Zhang SY, Fu Z et al. Effective detection and quantification of dietetically absorbed plant microRNA in human plasma. J. Nutr. Biochem. 26(5), 505-512 (2015).
10. Zhang L, Hou DX, Chen $X$ et al. Exogenous plant MIR168a specifically targets mammalian LDLRAP1: evidence of cross-kingdom regulation by microRNA. Cell Res. 22(1), 273-274 (2012).

11. Oestergaard $\mathrm{H}$, Olsen $\mathrm{OH}$, Larsen $\mathrm{KS}$, Stennicke H. Human coagulation factor VII polypeptides. US20170198274A1 (2017)

12. Olson NC, Raffield LM, Lange LA et al. Associations of activated coagulation factor VII and factor VIla-antithrombin levels with genome-wide polymorphisms and cardiovascular disease risk. J. Thromb. Haemost. 16(1), 19-30 (2018).

13. Dehelian $\mathrm{D}$, Palowitch $\mathrm{G}$, Fritzinger $\mathrm{N}$ et al. Conformational changes in complement component 3 upon activation or thrombomodulin binding. Biophys. J. 110(3), 44a (2016).

14. Warthmann N, Chen $H$, Ossowski S, Weigel D, Herve P. Highly specific gene silencing by artificial miRNAs in rice. PLOS ONE 3(3), e1829 (2008).

15. Yan F, Lu YW, Wu GT et al. A simplified method for constructing artificial microRNAs based on the osa-MIR528 precursor. J. Biotechnol. 160(3-4), 146-150 (2012).

16. Holsters M, De Waele D, Depicker A, Messens E, Van Montagu M, Schell J. Transfection and transformation of Agrobacterium tumefaciens. Mol. Gen. Genet. 163(2), 181-187 (1978).
17. Park S, Elless MP, Park J et al. Sensory analysis of calcium-biofortified lettuce. Plant Biotechnol. J. 7(1), 106-117 (2009)

18. Murashige T, Skoog F. A revised medium for rapid growth and bio assays with tobacco tissue cultures. growth and bio assays with tobacco tissu
Physiol. Plant. 15(3), 473-497 (1962).

19. Kim MJ, Moon Y, Tou JC, Mou BQ, Waterland NL. Nutritional value, bioactive compounds and health benefits of lettuce (Lactuca sativa L.). J. Food Compos. Anal. 49, 19-34 (2016).

20. Edros RZ, Mcdonnell S, Al-Rubeai M. Using molecular markers to characterize productivity in Chinese hamste ovary cell lines. PLOS ONE 8(10), e75935 (2013).

21. Hou $Y H$, Jeyaraj $A$, Zhang $X$, Wei CL. Absolute quantification of microRNAs in green tea (Camellia sinensis)
by stem-loop quantitative real-time PCR. J. Sci. Food Agr. 97(9), 2975-2981 (2017).

22. Livak KJ, Schmittgen TD. Analysis of relative gene expression data using real-time quantitative $\mathrm{PCR}$ and the 2(-Delta Delta C(T)) method. Methods 25(4), 402-408 (2001). 